\title{
Criminal Insanity, Psychosis and Impaired Reality Testing in Norwegian Law
}

\section{Introduction}

Norwegian criminal law has a long tradition of using a 'medical model' for the definition of criminal insanity. ${ }^{1}$ Under section 20 first paragraph, letter $b$ of the Penal Code, ${ }^{2}$ a defendant who is psychotic at the time of the offence is absolved from criminal responsibility. This provision essentially equates criminal insanity with psychosis, and does not operate with any criteria requiring causality, or any other additional (psychological) criteria as is the case in many countries. ${ }^{3}$

It has been questioned, particularly after the 22 July case, ${ }^{4}$ whether the medical

* $\quad$ Linda Gröning, Faculty of Law, University of Bergen; Centre for Research and Education in Forensic Psychiatry, Haukeland University Hospital of Bergen.

Unn Kristin Haukvik, University of Oslo, Institute for Clinical Medecine, Department of Adult Psychiatry; NORMENT, Norwegian Centre for Mental Health Research, Oslo University Hospital.

Karl Heinrik Melle, St Olav's University Hospital, Trondheim; The Norwegian Board of Forensic Medicine.

1 See below in section 3.

2 LOV-2005-05-20-28, the Penal Code (Lov om straff). For an English translation, see https:// lovdata.no/dokument/NLE/lov/2005-05-20-28 (All weblinks last accessed $9^{\text {th }}$ September 2019)

3 For a comparative overview of criminal insanity regulations, see Simon \& Ahn-Redding, The Insanity defense, the world over (Lexington books 2008); Stuckenberg, 'Comparing legal approaches: mental disorders as grounds for excluding criminal responsibility' Bergen Journal of Criminal Law and Criminal Justice, 4(1) (2016) pp. 48-64.

$4 \quad$ The case that followed Anders Behring Breivik's killing of 77 people in Oslo and on Utøya in Norway on 22 July 2011, Oslo District Court, TOSLO-2011-1888627-24 (RG-2012-1153), available in English at http://lovdata.no/info/information in english. 
model gives an erroneous delimitation of who should be absolved from criminal responsibility and provides forensic experts with too much power in this determination. On the basis of this critique, new rules have now been proposed that will remove the psychosis criterion and replace it with a rule that opens the doors for a greater degree of judicial discretion. ${ }^{5}$ However, also under this new rule, psychosis remains central to criminal insanity. ${ }^{6}$ The concept of psychosis is also central to insanity judgments in most countries and can be viewed as a common core of the western idea of criminal incapacity. ${ }^{7}$

Core questions are, then, how psychosis is, and should be, related to criminal insanity. In what way, to what extent, and on what grounds, is psychosis relevant for insanity? Although Norwegian law explicitly ties criminal insanity to psychosis, it does not provide clear answers to these questions. In particular, in cases where the offence(s) seems to be rational and/or planned, the understanding of insanity and psychosis is a matter of debate. There is no comprehensive account in Norwegian criminal law theory clarifying the legal relevance of psychosis. Given this background, we aim in this article to contribute to such a clarification by gathering together legal, forensic, and clinical empirical perspectives on the legal meaning and relevance of psychosis. Our clarification will include the interrelated problems of the law's definition (of psychosis and insanity) and justification (why and to what extent psychosis is legally relevant). Although the current Norwegian criminal insanity rule will serve as our reference point, such clarification is of broad international relevance.

The outline of the article will be as follows. Firstly, we will in sections $2-4$ provide a somewhat deeper contextualisation and explanation of the significance of psychosis in Norwegian law. These sections will include an overview of the criminal insanity regulation, the background and justifications for tying psychosis to criminal insanity, and a deeper explanation of the legal criteria of psychosis and its application in legal practice. With this in mind, we will in sections 5-6 explain how the legal criterion of psychosis is operationalised in forensic practice. As we will see, there is no full clarification about the legal relevance of psychosis. We will in section 7 draw some intermediate conclusions about this lack of a clear legal definition and point to some practical/clinical challenges as regards the evidence of psychosis. In order to gain greater understanding, we will in sections 8-10 investigate further the medical understanding of psychosis. Here, we will explore the medical definition of psychosis

5 See Lovvedtak 60 (2018-2019) and Innst. 296 L (2018-2019). For a further explanation of the proposal and its background, see Gröning, 'Hvordan skal vi avgjøre om alvorlig sinnslidelse innebærer utilregnelighet? Refleksjoner om lovforslaget i Prop. 154 L (2016-2017)', Bergen Journal of Criminal Law and Criminal Justice, 5(1) (2017) pp. 77-85; Gröning and Rieber Mohn, 'NOU 2014: 10 - proposal for new rules regarding criminal insanity and related issues, Norway post 22 July', Bergen Journal of Criminal Law and Criminal Justice, 3(1) (2015) pp. 109-131.

6 See Prop. 154 L (2016-2017) Endringer i straffeloven og straffeprosessloven mv. (skyldevne, samfunnsvern og sakkyndighet) p. 13 and p. 69, and Innst. 296 L (2018-2019) pp. 3-4.

$7 \quad$ Moore 2015, 'The quest for a responsible responsibility test: Norwegian law after Breivik', Criminal Law and Philosophy 9(4) (2015) pp. 645-693. 
and the relationship between psychosis and impaired reality testing from a medical perspective. Finally, we will in section 11 bring these perspectives together, draw some conclusions about the current state of law, and provide some recommendations for the future.

\section{Criminal Insanity in Norwegian Law: Overview}

In order to discuss the significance of psychosis for criminal insanity in Norwegian law, first it is necessary to understand the general structure of the relevant rules and concepts. A good place to begin is, therefore, with the core assumption of the criminal law that individuals generally have the capacity to act criminally responsibly, i.e., have criminal capacity. Individuals do not always make use of this capacity, but normally they are expected to do so.

Criminal capacity at the time of the offence is in Norwegian law, as in most countries, a basic condition for criminal responsibility. Only certain conditions that are currently specified in the Penal Code section 20, first paragraph, letters a-d entail criminal incapacity and lead to unconditional exoneration from criminal responsibility. This rule determines that the perpetrator is absolved from criminal responsibility if he or she was: a) under 15 years old, b) psychotic, c) severely mentally disabled, or d) had a severe impairment of consciousness at the time of the offence. ${ }^{8}$ The age limit of 15 years is absolute and will not be dealt with further in this article. ${ }^{9}$ The criterion 'psychotic' provides the rule about criminal insanity that will be our focus in the following. This criterion refers to the medical characterisation of psychosis, but the provision requires, as we will develop below in section 4, that the psychosis be discernible and have a qualitative impact on the perpetrator's ability to comprehend reality at the time of the offence. It requires, more specifically, that the perpetrator's ability to make a realistic assessment of his/her relationship to the surrounding world was significantly impaired at the time of the act. ${ }^{10}$ The criterion 'severely mentally disabled' refers to offenders with seriously impaired intellectual capacity. Whether this criterion is fulfilled depends on an overall evaluation of the functioning and intellectual capacities of the offender, where a functioning similar to an intelligence quotient below 55 normally entails incapacity. ${ }^{11}$ Finally, 'severe impairment

$8 \quad$ For a further explanation of these rules, see Gröning, Jacobsen \& Husabø, Frihet, forbrytelse og straff: en systematisk fremstilling av norsk strafferett (Fagbokforlaget 2016) pp. 484-502.

9 See further Gröning, 'Kriminell lavalder - noen utgangspunkter', Tidsskrift for strafferett 4 (2014) pp. 314-332.

10 See Ot. prp. nr. 87 (1993-1994) p. 22, NOU 1990: 5 p. 38, NOU 2014: 10 p. 49, and Prop. 154 L (2016-2017). See also Gröning, Husabø \& Jacobsen (2016) p. 495.

11 See Søndenaa et al, 'Criminal Responsibility and Challenges in the Criminal Justice System for People with Intellectual Disability in Norway', Bergen Journal of Criminal Law and Criminal Justice 7(1) 2019, pp. 97-109. 
of consciousness' refers to cases where the perpetrator has acted without perceiving their surroundings whatsoever. An indication that the person was in a state which may qualify for this criterion is a substantial loss of memory assumed caused by loss of the ability to memorize due to the persons mental state. (imprinting). Thus, the person can act, but is to a large extent without ability to control or critically evaluate how he or she acts. Such cases can, for example, occur during sleepwalking or an epileptic seizure. In the second paragraph of section 20 of the Penal Code, there is an exception for incapacity triggered by self-induced intoxication that is applicable to criminal incapacity due to psychosis and impairment of consciousness. ${ }^{12}$

These circumstances entailing criminal incapacity are all understood as excuses in the general structure of the criminal law. The basic justification for excusing perpetrators is, in this regard, rooted in the principle of guilt/fault. Those are excluded from responsibility who (at the time of the act) are understood to lack the basic capacity of criminally responsible behaviour, and thus cannot be blamed. The more specific justification for excluding psychotic offenders from responsibility will be explained below.

It worth noting here that the various grounds for criminal incapacity, in contrast to many countries, are all defined by specifying a particular condition-young age, unconsciousness, mental retardation, or psychosis-which, when established at the time of the offence, lead to unconditional exoneration from criminal responsibility. As will be described below, criminal insanity as a matter of psychosis reflects a specific medical model. It should also be noted that, in Norwegian law, criminal insanity, as a matter of mental disorder as an excuse, is separated in the Norwegian regulation from incapacity due to mental disability and consciousness impairments. This is different from what is the case in many countries.

When it comes to evidence, it is the perpetrator's criminal capacity (and not incapacity) at the time of the offence which much be proven by the prosecution. ${ }^{13}$ Thus, criminal insanity is not constructed as a defence, such as is typically the case in Anglo-American law. Instead, criminal incapacity and insanity are understood as circumstances that exempt a defendant from an otherwise wrongful and criminalised act, where criminal capacity is the requirement for responsibility. The duty of the court is to determine whether the defendant fulfilled this requirement, disregarding the defendant's own view on his/her capacity. As we will return to below, forensic experts often have decisive influence on the result of this process of determination.

The general standard of proof is often formulated by stating that 'any reasonable doubt should benefit the defendant. ${ }^{34}$ Certain proof and solid persuasion are nec-

12 For a discussion on this exception, see Gröning \& Myklebust, 'Intoxication and self-induced criminal incapacity in Norwegian law', Bergen Journal of Criminal Law and Criminal Justice 6(1) (2018) pp. 68-91.

13 Se Ot. Prp. Nr. 11 (1928) p. 5, Rt. 1979 p. 143, and NOU 2014: 10 pp. 185-186.

14 See Kohlflaath 'Bevist utover enhver rimelig tvil', Tidsskrift for Rettsvitenskap 124(2) (2011) pp. 135-196 for a discussion about the meaning of this standard of proof. 
essary. This is the same standard of proof that is enshrined in the legal systems of most civilised nations, and it has its ethical roots in a desire to avoid the conviction of innocent individuals. The Norwegian Supreme Court has ruled that this general standard of proof applies to all preconditions of criminal responsibility, including the requirement of criminal capacity. The Supreme Court has, on the other hand, also ruled that the same standard of proof cannot be demanded when the determination of criminal capacity concerns whether the defendant was insane and psychotic. ${ }^{15}$ Which standard of proof applies to this determination is not fully clear. It follows from previous judgements that a balance of probability standard is clearly not sufficient, but the higher threshold has not yet been clarified. Many argue, however, that the threshold is only slightly lower than the general standard of proof requiring no reasonable doubt. ${ }^{16}$

Although the court has the ultimate say on whether the perpetrator was psychotic and thus insane at the time of the offence, forensic experts have, in practice, had considerable, and often decisive, influence on the result. Typically, the courts refer to the evaluations and conclusions from forensic experts in their judgments, and build their legal conclusions upon these. ${ }^{17}$ Forensic experts are appointed by the court, not by the parties. ${ }^{18}$ It is standard that two independent experts are appointed by the court. The courts use a standard mandate, composed in collaboration between the Prosecutor General, The Court Administration, and the Norwegian Board of Forensic Medicine. ${ }^{19}$ Under this mandate the forensic experts are asked to evaluate the mental condition of the perpetrator in relation to the psychosis criterion in the Penal Code section 20. More specifically, the experts diagnose the defendant following the ICD-10 as a basis for the forensic evaluation. On this basis, they will then evaluate whether the perpetrator was psychotic at the time of the offence as the Penal Code requires, which also requires a legal understanding of this criterion. ${ }^{20}$ In order to secure a certain quality and provide for a uniform forensic practice, the Norwegian Board of Forensic Medicine controls all of these evaluations. The strict standard of proof has generally had the result that when the experts unanimously conclude with psychosis, and this is approved by the forensic board, the court follows their conclusion. In cases where the experts conclude with sanity but expresses doubt, or when the ex-

15 See for comparison Rt. 1979 p. 143, p. 147; Rt. 1990 p. 586, p. 587; Rt. 1998 p. 1945, p. 1947; Rt. 2003 p. 23 paragraph 13 and Rt. 2007 p. 1217 paragraph 64.

16 See Gröning, Husabø \& Jacobsen (2016) pp. 489-490, Strandbakken, Uskyldspresumsjonen 'In dubio pro reo', (Fagbokforlaget 2003) p. 407, and Løvlie, Rettslige faktabegreper (Gyldendal 2014) p. 359.

17 See further below in section 4.2.

18 It should here be noted that according to Norwegian law, the prosecution has a duty to be objective, see Criminal Procedure Act sections 55 and 226. See further Kjelby, Påtalerett (Cappelen Damm 2017) pp. 241-257.

19 See Newsletter no. 22 from the Norwegian Board of Forensic Medicine for the content of this mandate.

$20 \quad$ NOU 1990: 5 p. 42. 
perts conclude different from each other, the court must provide a more independent evaluation. ${ }^{21}$ Our impression is, however, that these cases are less frequent.

According to section 62 of the Penal Code, the court may decide to commit to compulsory psychiatric care an offender who is not accountable pursuant to section 20 first paragraph letter b. According to the Penal Code, this is a 'special criminal sanction' that is not punishment. Section 62 regulates two different forms of such compulsory care: one that is time unlimited (and can be prolonged as long as there is a risk that the offender may commit new serious crimes) and one that is time limited to a maximum of three years for offenders who commit less serious offences. The risk evaluation is made on the background of forensic expert evaluations, where the offender's conduct, illness progression, and mental functional capacity are central aspects. ${ }^{22}$

\section{The Medical Model: Background and Justifications}

The medical model for the definition of criminal insanity is characterised by identifying insanity with some form of mental disorder exclusively. Under section 20 first paragraph, letter $b$ of the Criminal Code, a defendant who is psychotic at the time of the act is absolved from criminal responsibility. This rule does not operate with any criteria requiring that the disorder affected the defendant's cognitive or control capacities with regard to the commission of the crime.

This current medical model with the psychosis criterion was introduced into section 44 of the former 1902 Penal Code by an amendment in 1997 that entered into force in 2002. ${ }^{23}$ However, the practice of using a medical model in Norwegian law significantly predates this. Already, the 1842 Criminal Code was to a certain extent built upon a medical model, and it was fully established in 1929 when the 1902 Penal Code was revised. ${ }^{24}$ In the earlier version of the rule, however, the legal criteria for insanity was 'sinnssyk', which translates precisely as 'insane. This criterion then also included mental retardation of high degree and serious instances of autism spectrum disorders. Through the 1997 amendment, this criterion was removed, and was split into the two new criteria that today are specified in section 20 letter b and c-'psy-

$21 \quad$ See further below in section 4.2 .

22 See further in Mindestrømmen, 'Impending Danger: The Meaning of Danger as a Legal Requirement for Involuntary Psychiatric Treatment in the Norwegian Criminal Justice System', Bergen Journal of Criminal Law and Criminal Justice 7(1) 2019, pp 110-135; Holst, 'CourtOrdered Compulsory Psychiatric Care and the Prosecutor's Control Function', Bergen Journal of Criminal Law and Criminal Justice 7(1) 2019, pp 136-147.

$23 \quad$ Lov 17. januar 1997 no. 11. See Ot.prp. nr. 87 (1993-1994) Om lov om endringer i straffeloven m.v. (strafferettslige utilregenlighetsregler og særreaksjoner) for the justifications for this amendment.

24 See Skålevåg, Utilregnelighet: En historie om rett og medisin (Pax Forlag 2016) for the historical development of the medical model in Norway. 
chotic' and 'mentally retarded to high degree'. An unintended, but problematic result of this change was that those with severe autism spectrum disorders now apparently fell outside the scope of the rule. The rule with the psychosis criterion was retained without changes in section 20 in the current 2005 Penal Code.

This rule has not been subject to much attention until the criminal case in the aftermath of the terrorist attack in the centre of Oslo and on Utøya on 22 July 2011 triggered a wide-ranging discussion about its adequacy. With this discussion as backdrop, a law commission was appointed to investigate the need for changes. This commission proposed in NOU 2014:10 to preserve the medical model, though in a considerably watered-down form that also includes 'conditions that are equated with psychosis. ${ }^{25}$ This proposal was, however, not followed by the Norwegian Ministry of Justice and Public Security, who delivered Prop. 154 L (2016-2017) in June 2017. The Ministry proposed, instead, a rule that removes the psychosis criterion and replaces it with a criterion that requires that the defendant was insane due to serious mental disorder' in order to be absolved from responsibility. ${ }^{26}$ The intention, similar to that of the law commission, was to introduce a criterion that makes it possible to include other conditions than psychosis, provided that they are serious enough, while retaining psychosis as the central condition for excuse. ${ }^{27}$ At the same time, the proposed rule allows for significant judicial discretion in regard to defining the more specific legal cut-off point. ${ }^{28}$ Particularly for this reason, the proposal from the Ministry has been widely criticised. The majority of the Justice committee in the parliament shared this critical view, and recommended that the proposal was sent back to the Ministry for further consideration. ${ }^{29}$ However, the minority that recommended that the Ministry's proposal was enacted consisted of representatives for the political parties in the government. These political parties have majority in the Parliament. Therefore, the voting in the Parliament was in favour of the proposal, with 52 against 46 votes. Accordingly, there will be a law reform. In any case, this law reform will not change the core characteristics of the medical model tradition in Norway; that mental disorder is sufficient for insanity. Although the word 'psychotic' will be removed, insanity will still be determined only in relation to the severity of the defendant's mental disorder. The severity of a psychosis will still remain central. ${ }^{30}$

25 The proposed rule was that 'A person whom the court deems to have been psychotic at the time of committing the act or in a condition which-due to reduced functioning, disordered thinking, or otherwise to the inability to comprehend their relationship with their surroundings - must be equated with psychosis, is free from criminal responsibility. See further Gröning \& Rieber Mohn (2015).

26 For a commentary on this proposal, see Gröning (2017). See also Gröning \& Myklebust (2018).

27 Prop. 154 L (2016-2017) pp. 64-70.

28 It should be mentioned that psychopathy is explicitly excluded from the sphere of relevant conditions, see Prop 154 L (2016-2017) p. 13 and pp. 76-77. See also NOU 2014: 10 p. 130.

29 See Innst. 296 L (2018-2019) pp 3-4 and pp. 8-9.

30 See Prop. 154 L (2016-2017) pp. 13 and 69, and Innst. 296 L (2018-2019) pp 3-4. 
Why has Norway established such a unique medical model? The medical model is often understood as an expression of the view that the impact of a mental disorder on the crime is irrelevant in Norwegian law. This is true if the focus is only on the court evaluation. However, the medical model was (and still is) most of all justified by arguments about legal certainty and an adequate functional division between the legislator and the courts. In the preparatory works it is stated that deciding the question of exemption from punishment should depend as little as possible on the judge's own discretion. Conditions of criminal insanity must be therefore be described in terminology that is recognised in psychiatric science. ${ }^{31}$ This focus on legal certainty is generally strong in Norwegian criminal law. ${ }^{32}$

Furthermore, at the legislative level, it is precisely the view that psychosis impacts in a certain way on the perpetrator's capacity for responsible behaviour that has been a primary justification. Generally, justifications for punishment in Norwegian law emphasise that criminal responsibility presupposes that the perpetrator has had a choice of (more than one) action and can be blamed for the choice taken. It is here the principle of guilt/fault that is the primary foundation: that only those that could and should have acted differently, and therefore can be blamed, should be held responsible and punished. Certain offenders must, however, be deemed to be in such a confused and abnormal state of mind at the time of the offence that they should not be held accountable for their actions. Offenders who were 'psychotic' at the time of the offence, and with a pronounced intensity of psychotic symptoms have, in this regard, been assumed to lack this capacity for responsible behaviour. ${ }^{33}$ In addition to this guilt-based justification for the psychosis criterion, crime prevention is emphasised as another purpose of law. The view is typically that there is no benefit from holding liable those who are in such a confused and abnormal state of mind. The criminal justice system's regulating effect on behaviour-that is, its ability to induce members of the public to obey the law through deterrence and the formation of norms-is not weakened by absolving these persons of criminal responsibility. ${ }^{34}$

The establishment of the medical model must, however, also be understood in light of the development of psychiatry in Norway and its influence on the legal understanding of insanity. ${ }^{35}$ The development of the medical model in Norway was surrounded by an atmosphere of scientific optimism, and the belief that insanity could be identified by psychiatry, through scientific methods. ${ }^{36}$

\footnotetext{
31 See, inter alia, Ot.prp. nr. 87 (1993-1994) p. 28.

32 See Gröning, Husabø \& Jacobsen (2016).

33 See NOU 2014: 10 p. 111.

34 See NOU 2014: 10 pp. 85-86. See also Gröning \& Rieber Mohn (2015), p. 113.

35 For an explanation of the historical development of the medical model, see Skålevåg (2016) and Skålevåg, 'Sykdom og tilregnelighet - fra sakkyndighetens historie', Tidsskrift for norsk legeforening 122(1) (2002) pp. 65-68.

36 See Skålevåg (2016).
} 


\title{
4. The Understanding of Psychosis in Law and Legal Practice
}

\subsection{Explanations in the Legal Sources}

Let us then take a closer look at how the psychosis criterion has been explained in the legal sources. In the preparatory works, the Ministry of Justice provides the following explanation that has been cited in many court cases and discussed in the literature:

\begin{abstract}
'When considering the type of conditions to be considered as psychoses in the sense of the Penal Code, decisive importance must be attached to the way in which psychiatry at any given time defines the concept of psychosis. Today, psychiatrists agree that the principal characteristic of a psychosis is that the relationship to reality is significantly disturbed. The ability to react adequately to ordinary impressions and influences is lacking. The psychotic person often loses control over his thoughts, emotions and actions. Intellectual functions, on the contrary, may be intact. The dividing line between psychosis and other mental disorders is not sharp. ${ }^{37}$
\end{abstract}

This quotation provides the general understanding of the law's psychosis criterion, but also highlights some controversial points. To begin with the uncontested, psychosis constituting criminal insanity is in accordance with the medical conception of impaired reality testing, and more specifically of significantly impaired reality testing. ${ }^{38}$ What matters to the law is, in this regard, that the perpetrator was psychotic at the time of the offence.

In order to understand the law properly, we must here consider the distinction between psychosis-symptoms, psychosis as state, and psychotic disorders. Psychotic disorders are classified according to descriptive, consensus-based, diagnostic manuals. The two major manuals are the Diagnostic and Statistical Manual of Mental Disorders (currently in its fifth edition, DSM-5) from the American Psychiatric Association, ${ }^{39}$ and the international classification system for mental disorders (currently in its tenth version, ICD-10) from the World Health Organization, the latter of which is used in the Norwegian forensic context. ${ }^{40}$ Psychosis symptoms are signs that indicate (a state or a disorder of) psychosis. As we will return to, neither the ICD-10 or the DSM-5 have a formal definition of the term psychosis. ${ }^{41}$ Instead, the DSM-5 defines 'psychotic features' as 'features characterised by delusions, hallucinations, and formal

37 See inter alia, Ot.prp. no. 87 (1993-1994) p. 22, Rt. 2008 p. 549 section 33, and Gröning, Husabø \& Jacobsen (2016) pp. 494-497.

38 This will also be the case under the proposed new rule, see Innst. 296 L (2018-2019) pp. 2-3.

39 American Psychiatric Association, Diagnostic and Statistical Manual of Mental Disorders, 5th Edition: DSM-5 (American Psychiatric Publishing 2013).

40 World Health Organization, The ICD-10 Classification of Mental and Behavioural Disorders: Clinical Descriptions and Diagnostic Guidelines (World Health Organization 1992).

$41 \quad$ See below in section 9. 
thought disorder', and in the ICD-10 the term 'psychotic' describes 'the presence of hallucinations, delusions, or a limited number of severe abnormalities of behaviour, such as gross excitement and overactivity, marked psychomotor retardation, and catatonic behaviour'. These features are generally understood as psychosis symptoms. Psychosis as a state amounts essentially to impaired reality testing, and it is this aspect that is relevant to law. As there is a lack of a definition of psychosis, it is also unclear how impaired reality testing should be understood. It is, however, common to interpret the law's psychosis criterion as a requirement that the psychosis must be discernible at the time of the offence through obvious symptoms. As we will return to, this relation between symptoms and impaired reality testing is complex. ${ }^{42}$

Disregarding this complexity, it is clear that the legal criterion requires that the perpetrator was in an (active) state of psychosis at the time of the act. It is, therefore, not sufficient for the perpetrator to have a diagnosis of a psychotic disorder, such as schizophrenia. A person who suffers from a psychotic disorder and receives effective medication, or is otherwise in better health due to natural fluctuation in psychosis symptoms, may not be psychotic at the time of the offence. If this is the case, he/she is not criminally insane according to Norwegian criminal law. ${ }^{43}$

Although generally acknowledged, the distinction between having a diagnosis of a psychotic disorder, and being psychotic at the time of the offence has resulted in some confusion in the legal discourse. ${ }^{44}$ When the psychosis criterion was enacted it was suggested by the Special Sanctions Committee that the rule should specify that 'A person who was psychotic at the time of committing the act and hence unable to make a realistic assessment of his relationship to the surrounding world [emphasis added] shall not be liable to a penalty. ${ }^{35}$ The Ministry, however, did not support this proposed specification, with the justification that:

'It must be expected that persons who are to practice this provision, i.e., lawyers with the help of psychiatrists, are aware of the characteristics of a psychotic state. For them, any specification is unnecessary. However, people in general probably know little about the characteristics of a psychosis. But for them, a specification would, in the Ministry's view, be confusing rather than informative, since it is conceivable that there are psychotic offenders who, to a greater or lesser degree, have the ability to make realistic assessments. ${ }^{36}$

$42 \quad$ See below in section 9.

43 In this regard, Norwegian law operates with a relatively high threshold for criminal insanity. As a comparative example, the Danish criminal insanity rule includes those with a diagnosis of a psychotic disorder, and there is no equivalent requirement of seriousness, See further Kamber, 'Psykisk syge lovovertrædere i et komparativt lys', Nordisk tidsskrift for kriminalvidenskab 100(3) (2013) pp. 358-368.

44 See, inter alia, Rosenqvist 'Utilregnelighetsregelen - moden for revisjon?', Tidsskrift for den Norske Legeforening 132(7) (2012) pp. 843-844.

$45 \quad$ NOU 1990: 5 p. 38 and p. 51.

46 Ot.prp. nr. 87 (1993-1994) p. 28. 
In our view, the proposed specification should have been enacted, as it makes it clear that having a diagnosis is not sufficient to fulfil the legal criterion.

A more complicated matter is how it should be interpreted that the legal psychosis criterion requires a significantly impaired reality testing. In the preparatory works it is explained that the offender's lack of ability to make a realistic assessment of his relationship to the surrounding world must be relatively general, i.e., the impairment must include significant aspects of reality for the offender to be declared psychotic. ${ }^{47}$ On the other hand, an all-encompassing failure of the ability to assess reality is not necessarily required. A flawed perception of reality in a limited sector may, for the patient, assume such dimensions and have such consequences for his relationship to the surrounding world that it would be correct to evaluate him as psychotic.

However, this explanation does not fully clarify what impaired reality testing amounts to; for instance, to what extent and in what way it involves quantitative and/ or qualitative dimensions of psychopathology. Another challenge is whether the legal cut-off point for being psychotic should be understood as stricter compared to the clinical one. In the literature, and also in forensic practice that we will look at below, it is argued that the legal criterion requires the psychotic state to be of a certain seriousness. This means that a dimensional perspective is taken, implying that it is possible to quantify impaired reality testing in terms of more or less psychotic. We will return to this matter and discuss whether and how this legal cut-off point can be operationalised from a medical research point of view. ${ }^{48}$

\subsection{The Interpretation of the Psychosis Criterion in Legal Judgments}

In criminal insanity cases it is the court that has the final say about whether a defendant is psychotic and should be absolved from responsibility. This question is then answered through the application of the psychosis criterion in individual cases, which involves interpretation of its legal meaning. Generally, however, the courts do not provide any further clarification of the legal meaning of the psychosis criterion other than what follows from the preparatory works. What is more, the courts to a significant extent rely on forensic experts and justify their legal conclusions through clinical and diagnostic evaluations. ${ }^{49}$ Therefore, the courts' legal argumentation about insanity is in most cases full of medical language, and hinges largely upon psychiatric diagnoses and symptoms. The typical structure of the legal reasoning is the following. First, the evaluations of the experts and other (medical) witnesses are described. These provide a diagnosis of the defendant, and an explanation of the ob-

\footnotetext{
$47 \quad$ See NOU 1990: 5 p. 38. See also NOU 2014:10 p. 49 and Prop. 154 L. (2016-2017) p. 21.

48 See below in section 9 and 10.

49 This is based upon an investigation of all published judgments between 01.01.2013-01.11.2018, see https://lovdata.no.
} 
served symptoms and dysfunctions. On this basis they also conclude on the question of psychosis and impaired reality testing at the time of the offence. After describing these expert evaluations, the court typically gives its verdict, briefly stating that the defendant was/was not psychotic according to section 20 first section letter $b$ of the Penal Code.

Reading criminal insanity judgments often leaves one wondering how the court found its way from the diagnostic evaluation of the offender, to the legal conclusion about psychosis and insanity.

In cases where there is disagreement between the experts, the courts provide a more independent evaluation. However, the courts in these cases typically do not provide any clarification of the legal cut-off points for psychosis amounting to criminal insanity. Instead, the focus is on reviewing the medical statements of the experts. The well-known Breivik case provides an illustrative example, although it contained an unusually long evaluation from the court. In this case, two pairs of experts concluded differently about his diagnosis and sanity; the first pair of experts evaluated him as psychotic, and the second pair evaluated him as non-psychotic. ${ }^{50} \mathrm{~A}$ main point of controversy was whether Breivik's beliefs were an expression of grandiose delusions present in schizophrenia or extreme beliefs indicating his terrorist motivation. The court agued, inter alia, that:

'The defendant has in a fanatical and cynical manner maintained that the selection of victims and object for his misdeeds on 22 July 2011 was politically motivated. It is difficult for the Court to see that his conceptions of murders and terrorist acts to attain a future political goal-regardless how incomprehensible and reproachable they may becan be "completely impossible", which is how this diagnostic criterion is normally applied according to information at hand. [...]

The activities described above show that the defendant had stamina, impulse control and good cognitive functions related to the tasks he assigned himself. The Court finds the defendant's ability to plan and implement in these various areas hard to reconcile with untreated paranoid schizophrenia with a gradual deterioration from 2006.51

The court finally concluded that Breivik was sane, mainly by showing that he did not have psychotic symptoms fulfilling an ICD-10 diagnosis of paranoid schizophrenia. As is typical in insanity cases, this link between diagnostic categories and legal standards was not clarified or justified. In addition, the judgement was based on faulty statements about the relevant disorders, for instance that Breivik's ability to plan his acts was hard to reconcile with schizophrenia. ${ }^{52}$

50 See Oslo District Court, TOSLO-2011-1888627-24 (RG-2012-1153), available in English at http://lovdata.no/info/information in english. See also, Melle 'The Breivik case and what psychiatrists can learn from it', World Psychiatry 12(1) (2013) pp. 16-21.

51 See Oslo District Court, TOSLO-2011-1888627-24 (RG-2012-1153) p. 56.

52 Dahl, 'Erklæringer og dom i 22 juli saken - hva kan vi lære?', Tidsskrift for Den norske legeforening 133(12/13) (2013) pp. 1289-1290. 
It should here be noted that in some cases where the experts found that the defendant is not psychotic, the court concludes differently from the experts even when the experts agree with each other. Most often, however, the court then justifies its disagreement with the experts with reference to the strict standard of proof, and the fact that the experts' conclusion raises too much doubt about the defendant's condition. There are also a few examples in the case law of the court emphasising the weight of evidence other than the expert evaluation in its reasoning. In some of these cases, the court-or at least some members of it-may disagree with the forensic experts on the basis of other evidence, such as witness reports about the defendant's mental condition. In other cases, the court may agree with the experts' medical conclusion, but also emphasise these other sources of evidence as a basis for their own legal conclusion. ${ }^{53}$ Nevertheless, the courts in these cases typically do not provide any legal clarification of the cut-off point for insanity. It seems, in fact, somewhat unpredictable which aspects of the evidence about the defendant's condition the courts choose to emphasise as the bases for their verdict. Sometimes the courts point to the nature of the defendant's symptoms, such as hallucinations and delusions, but without further clarification, whereas at other times witness descriptions or the defendant's own explanations about his actions are emphasised.

In sum, court practice does not provide for further clarification of the psychosis criterion, or for what is required for an impaired reality testing to be serious enough to fulfil this criterion. Is it a matter of diagnoses, or of symptoms? And, if the latter, which symptoms? In order to seek a clearer understanding of the legal meaning of psychosis, we will now take a look at the operationalisation of the psychosis criterion in forensic practice.

\section{The Understanding of Psychosis in Forensic Practice}

The predominant role of forensic practice is to assist the court (and the prosecutors) with medical evaluations of whether the defendant was psychotic at the time of the offence, with a significantly impaired reality testing. The forensic evaluation will in this regard tie the legal psychosis criterion to an underlying medical conceptualisation of the severity of the psychosis. From the law's perspective, this link between the legal criterion and the medical concept of psychosis is, as we have explained above, understood to secure legal certainty. ${ }^{54}$ The tacit presumption is that forensic practice can provide a sufficiently clear and uniform understanding of psychosis and impaired reality testing that may provide the law with a clear cut-off point for insanity.

53 See Judgment from Gulating Lagmansrett 19.11.2015 (LG-2015-60583), Judgment from Borgarting lagmansrett 17.06.2013 (LB-2013-58668) and Judgment from Halden tingrett 22.03.2018 (THALD-2017-172135).

$54 \quad$ See section 3 above. 
However, this is not necessarily the case. There is no clear and uniform understanding about what impaired reality testing amounts to in forensic practice. Rather, the forensic field is characterised by a significant diversity in perspectives, which is also related to an underlying diversity in ordinary clinical practice. The high degree of institutional autonomy in Norway, where mental health institutions are often also geographically separated, may allow for 'local diagnostic schools'. ${ }^{55}$ This was also a main reason for the establishment of the National Board of Forensic Medicine that is understood to contribute a more consistent forensic practice.

A remaining core challenge is, however, the focus on criteria-based diagnostics. When forensic experts evaluate a defendant, they first establish a diagnosis based on the criteria listed in the ICD-10 manual. ${ }^{56}$ This is to provide a more transparent basis for the clinical (and the following legal) evaluation. ${ }^{57}$ As we will return to, an overt focus on diagnostic criteria may, however, shadow the legally relevant assessment of the person's ability to understand reality. A person may, as we have described, have symptoms and signs sufficient for a diagnosis of a psychotic disorder (following the ICD-10), without having a significantly distorted perception of reality as the law requires. The focus on ICD-10 as a basis for expert evaluations also seems to link criminal insanity to diagnostic categories, and to specific diagnoses. Paranoid schizophrenia is, in this regard, by far the most frequent diagnosis where Norwegian experts conclude that the defendant was psychotic and criminally insane.${ }^{58}$ At the same time, the ICD-10 does not provide a clear definition of what it means to be psychotic and reality distorted, but focuses on symptoms that are part of psychotic disorders. ${ }^{59}$ Psychiatrists and psychologists have therefore problematised the use of ICD-10 (and DSM) in clinical and forensic psychiatric practice. A main concern has also been that the diagnostic systems mainly focus on easily recognisable symptoms, not on the person's subjective experience of themselves and how they interpret the world

55 See Nordgaard, Jessen, Sæbye \& Parnas, 'Variability in clinical diagnoses during the ICD-8 and ICD-10 era', Social Psychiatry and Psychiatric Epidemiology 2016 for an investigation into diagnostic variation in Denmark.

56 This practice was established through a newsletter from the National Board of Forensic Medicine in February 2004 that provided a distinct recommendation that every person observed should be diagnosed according to the criteria in ICD-10. See newsletter no. 10, available at http://www.sivilrett.no/nyhetsbrev.339568.no.html.

57 A curiosity is here that the Danish forensic board has chosen to keep ICD-8 as a standard since the old system is more easily compatible with the Danish judicial system.

58 See, inter alia, Callahan, Steadman, McGreevy \& Robbins, 'The volume and characteristics of insanity defense pleas: an eight-state study', Bulletin of the American Academy of Psychiatry and the Law 19(4) (1991) pp. 331-338, and Perlin, 'The Insanity Defense: Nine Myths that Will not Go Away', in White, MD (ed.), The Insanity Defense: Multidisciplinary Views on its History, Trends and Controversies (Praeger 2017).

59 See Kvig \& Nilssen, 'Epistemologi og psykiatriske diagnoser: nødvendigheten av en fenomenologisk forståelse av psykotisk bevissthet', Tidsskrift for Norsk psykologforening 51(9) (2014) pp. 729-737 and Melle 'Rettspsykiatriske vurderinger', in Aarli, Hedlund \& Jebens (eds.), Bevis i straffesaker: Utvalgte emner (Gyldendal 2015) p. 665. 
around them - such as a phenomenological approach allows for. Thus, by focusing on signs and symptoms the experts may overlook other hallmarks of a psychotic state: that the perpetrator only manages to view himself and his surroundings from the first-person perspective (egocentric perspective) and lacks (or has lost) the ability to take any other perspective than their own. ${ }^{60}$

In our understanding, there is no conflict between using the modern criteria-oriented diagnostic symptoms and taking such a subjective-oriented phenomenological approach. Although the forensic experts are required to diagnose according to ICD-10, they are also, to a certain extent, required to embrace a phenomenological perspective. From such a perspective, impaired reality testing is in essence conceptualised as an understanding of reality that isn't shared by others in the population to which the person belongs (in-group). In other words, the person's understanding of reality is idiosyncratic. Although such a phenomenological perspective may come closer to grasping what impaired reality testing is about, it is not operationalised in clear clinical (or legal) cut-off points in forensic practice. Hence, there is no uniform understanding-or, even less, guidelines-securing transparency and equal treatment. This lack of clear cut-off points is reflected in the challenges to prove that a defendant was (sufficiently) psychotic at the time of the act, which, as we shall now explain, ultimately amounts to a discretion-based assessment.

\section{Identifying Psychosis in Forensic Practice}

\subsection{Central Perspectives and Approaches}

According to the standard mandate from the court or the prosecutor, the forensic experts are asked to evaluate whether the defendant was psychotic according to the Penal Code, i.e., whether the defendant's capacity for reality testing was significantly impaired at the time of the offence(s) or not. In order to fulfil this mandate, the experts have to seek knowledge about the defendant's state of mind. Basically, there are two sources for such knowledge: information from the defendant himself, and interpretations of his state of mind by other observers, based upon their observations of and contact with him. ${ }^{61}$ It is crucial to assess the person's own views, and the clinical interview is thus central in the experts' work. The experts must also use information from other sources, such as documents from the police, the correctional services, or

60 For a comment on the focus on signs and symptoms in the assessment of psychopathology, see Nelson, Parnas \& Sass, 'Disturbance of Minimal Self (Ipseity) in Schizophrenia: Clarification and Current Status', Schizophrenia Bulletin 40(3) (2014) pp. 479-482. See also Sass \& Parnas, 'Schizophrenia, Conciousness, and the Self', Schizophrenia Bulletin 29(3) (2003) pp. 427-444.

61 See Andenæs, Alminnelig strafferett, 6th ed., by Rieber Mohn \& Sæter (Universitetsforlaget 2016), p. 240. 
the health system. If the defendant refuses to cooperate, the forensic evaluation will be based solely upon this secondary information. ${ }^{62}$

Apart from the requirement that ICD-10 should be used, there are no unified diagnostic guidelines for Norwegian forensic practice. Diagnostic tools-such as the structured Mini-International Neuropsychiatric Interview (MINI) ${ }^{63}$ - that are routinely used in Norwegian psychiatric services for screening for psychiatric illnesses are also used by some forensic experts. The problem with these tools, however, is that they can be used to obtain a life-time diagnosis of a mental disorder, but little or no guidelines about the severity of the impairment which is understood to be central to law. In order to measure disorder severity, the diagnostic tools can be combined with rating scales. For instance, the Montgomery Asheim Depression Rating Scale (MADRS $)^{64}$ may be used to characterise the depth of a depression, the Young Mania Rating Scale (YMRS) ${ }^{65}$ may be used to measure the height of a manic episode, and the Positive and Negative Syndrome Scale (PANSS) ${ }^{66}$ may be used to chart the severity of a psychotic episode. It is noteworthy that these structured symptom mapping tools/interviews can only be used after a diagnosis has been established, in order to distinguish between different degrees of a symptom. These severity rating scales may be criticised for being a mechanical summing up of signs and symptoms. On the other hand, the rating scales can contribute to a more transparent clinical evaluation from the legal point of view, and improve the opportunity for the judge to examine and overrule the conclusions from the experts.

Determining the severity of a person's psychosis requires an experienced forensic expert who knows how to make persons with impaired reality testing expose this lack or shortage in ability during the interview. Central in this evaluation is the question of whether the perpetrator's beliefs, thoughts and behaviour are signs of a disordered relation to reality. Imagine, for instance, a person that expresses an opinion of being persecuted by the police, and where the forensic experts must evaluate if this is probable or not. The person is a criminal. The police are supposed to monitor the criminal population. A central task in deciding whether this belief is a sign of

62 In case of refusal to meet the forensic experts, the Criminal Procedure Act section 166 second paragraph allows the police to bring the person to the forensic experts, but the person doesn't have to cooperate. The Criminal Procedure Act section 167 regulates compulsory psychiatric hospital admission for observation.

63 Sheehan, Lecrubier, Sheehan, et al. 'The Mini-International Neuropsychiatric Interview (M.I.N.I.): the development and validation of a structured diagnostic psychiatric interview for DSM-IV and ICD-10', Journal of Clinical Psychiatry 59(20) (1998) pp. 22-33.

64 Montgomery \& Asberg, 'A new depression scale designed to be sensitive to change', British Journal of Psychiatry 134(4) (1979) pp. 382-89.

65 Young, Biggs, Ziegler \& Meyer 'A rating scale for mania: reliability, validity and sensitivity', British Journal of Psychiatry 133(5) (1978) pp. 429-35.

66 Kay et al. 'The positive and negative syndrome scale (PANSS) for schizophrenia', Schizophrenia Bulletin 13(2) (1987) pp. 261-276. 
impaired reality testing is the exploration of why the person thinks the police are after him. What does the perpetrator think the police's motives are? How does he/she know or suspect that the police are persecuting him? And, are there other symptoms or signs of a psychotic disorder?

Or, imagine a person belonging to a subgroup of fundamental Christians, who believes that he communicates directly with God and is convinced that God still sends prophets to earth. In the conversations with the forensic experts, he explains that his religious beliefs are in accordance with the rest of his congregation. He is utterly convinced that he is a prophet even when he is told that no one else in the congregation believes that. The other congregation members say that he has a serious drug dependency and finances his substance abuse by committing crimes, which is not consistent with being a prophet. He, however, rejects this view entirely and maintains, without any signs of doubt, that the others in the congregation will eventually change their minds. These examples show that impaired reality testing needs to be identified through comprehensive clinical evaluations that not only consist of identifying obvious psychosis symptoms, but that also integrate phenomenological and diagnostic perspectives.

Sometimes the impaired reality testing is strikingly obvious even for an uneducated person. In such cases, one might argue that the court has little use for forensic experts, apart from reducing the risk of being fooled by an individual merely simulating these symptoms. However, many cases are not that obvious, and the evaluation has to involve a certain degree of uncertainty. This requires competent expert interviews and evaluations. There are also certain specific challenges and reasons for uncertainty that we will now take a closer look at.

\subsection{The Challenge of the Time Gap from Criminal Act to Forensic Evaluation}

A specific challenge for the forensic experts (and for the judges) is the time component. The psychotic condition must be present at the time of the offence, but is always evaluated in retrospect-often months later, and under markedly different conditions and degree of subjective discomfort than at the time of the offence(s). When a crime has been committed it is therefore always important to have a psychiatric examination as close to the time of the incident as possible. In Norway, this can be achieved through a preliminary examination at the request of the police. ${ }^{67}$ Such a preliminary psychiatric examination close to the time of the incident may be a vital premise for the subsequent and more thorough psychiatric evaluation.

Nevertheless, the forensic evaluation must emphasise what the defendant tells about him/herself at the time of the offence. The experts must explain to the person observed that it is what he/she thought and felt at the time of action that is central, 
that he/she has to distinguish between what they thought then, afterthoughts, what he/she has read, has been told, has reasoned about in retrospect, and what he/she thinks today. If the examined person has developed a reality-based distance to his or her delusions it can help experts to get a clearer picture of the degree of lack of reality testing at the time of the offence(s). The longer the period of time between the event and the examination, the greater the uncertainty. This uncertainty in evaluating the defendant's state of mind in retrospect must be properly understood and communicated by the experts.

Since psychosis symptoms may fluctuate in severity over time, a person suffering from a psychotic disorder may move in and out of a state of being psychotic. The expression of mental states may be affected by internal and external stress such as physical fatigue, physical illness, lack of sleep, drug use, outwardly induced and/or inner emotional stress. How psychotic a person appears in a situation may, therefore, vary depending on a number of external and internal factors. A person can switch from being clearly psychotic in one situation, to appearing to hold a reality-based distance to their deviant ideas and experiences in a different situation.

Moreover, recovery may have occurred as a result of adequate and good treatment, no substance abuse, etc. Or the opposite, a deterioration of the illness may have occurred due to the fact that the disorder has developed further in a negative direction, continuation of drug use, etc. In some acute psychotic disorders with an affective component-typically in psychotic mania- symptoms and signs may fluctuate and vary considerably. At the time of the observation, the perpetrator has usually 'landed' (is in remission) from the manic state, or has developed a depressive episode. Therefore, at the time of the observation, there may be no clear psychotic symptoms. This stands in contrast to cases when the defendant suffers from schizophrenia or delusional disorder with more stable psychosis symptoms that are not linked to their affective state.

\subsection{The Challenge of Detecting Subtle Psychosis Symptoms}

Persons with a psychosis may, for several reasons, want to hide their symptoms. A typical example is a psychotic person who has a comprehensive paranoid system but is afraid of telling about his or her thoughts/ideas due to the fear that, if they tell about them, they may endanger themselves or anybody else they care about. Forensic experts then need to examine thoroughly for signs that may indicate psychosis and impaired reality testing, such as eccentric behaviour or a fall in mental, social, and occupational function. A slow and gradual fall in function is often obvious in retrospect. When the forensic experts observe indications of a probable or possible psychotic disorder, they must critically evaluate each sign or symptom, whilst at the same time trying to avoid seeing something that isn't there, and to avoid interpreting each sign and symptom as caused by something else. There may be many reasons 
for overlooking indistinct symptoms. For instance, thought disorders are considered to be core features of a psychotic state related to schizophrenia, but they are also frequently overlooked and interpreted as something else. They may be described in everyday language, without being clearly conceptualised as psychiatric symptoms. The person is, for instance, 'vague', 'answers besides the question', 'never reaches the point', or 'gives confusing answers'.

In forensic settings, the fear of being manipulated by a perpetrator can, in addition, lead to mistrust. A possible consequence might be that the forensic expert doesn't believe that the signs or clues are due of a genuine psychotic disorder. In order to recognise subtle psychosis symptoms, the expert must alternately focus on the whole picture, the patterns, the persons subjective experiences of the psychotic illness, but also on each one of the symptoms and signs. Sometimes rating scales can be helpful in describing in a more valid and reliable way what's been observed. When it comes to thought disorders, TALD ${ }^{68}$ can be helpful in naming concepts that are hard to catch.

The retrospective evaluation is further complicated if the person is capable of dissimulating, for example by not exposing the delusions motivating their acts, or by giving some kind of credible explanation as to why they acted the way they did. Usually, some signs can give guidance as to how credible the person's explanation is. A specific problem for forensic experts is that evaluation of evidence is the court's sole responsibility. When the experts nevertheless have to involve an assessment of the facts in their evaluation, before the court has concluded, they always have to make the reservation that the court may assess the facts differently. This may for instance be the case when the experts perceive that a person has acted on delusions, and that the person's own explanation in retrospect is a misdirection, but the court may conclude with the opposite. The danger of simulation and symptom aggravation at the time of the offence(s) is also a possibility, although experience indicates that, in reality, dissimulation is a much greater problem.

\section{Intermediate Conclusions: Vagueness and Practical Problems}

To draw some intermediate conclusions from the previous sections, it is clear that there are challenges tied both to the definition of psychosis, as a criterion for criminal insanity, and to proving the relevant state of psychosis. As regards the challenges of definition, we have discussed how Norwegian law ties insanity to psychosis as a matter of severely impaired reality testing. While it seems clear that a diagnosis is not sufficient, it is not so clear how we should understand the legal requirement of impaired reality testing, and whether and to what extent the legal requirement

68 Kircher et al., 'A rating scale for the assessment of objective and subjective formal Thought and Language Disorder (TALD)', Schizophrenia Research 160(1-3) (2014) pp. 216-221. 
amounts to a higher or different threshold when compared to the clinical evaluation of psychosis. In tying itself to a medical concept, the law lacks full concretisation of the legal cut-off points for criminal insanity. Although operating with a seemingly concrete psychosis criterion, our intermediate conclusion is that the criminal insanity rule in section 20 of the Penal Code is still legally vague. This problem will not be solved but will rather be reinforced with the proposed law reform.

This vagueness is not properly cured in forensic practice. Rather, this practice seems to suffer from the same vagueness problem as the law, and there is a lack of a uniform understanding of what is required for being psychotic, and how such a condition may be proved. The forensic experts operate with a large amount of discretion where the conclusion about the defendant's reality testing depends on an overall clinical assessment. There are no clear guidelines for evaluating whether the defendant lacks reality testing to a degree the law requires. It is also unclear how symptoms matter, and why. Although symptoms may be taken as indicators that a defendant lacks reality testing, they are not taken to prove the existence of psychosis. To a certain extent it rather seems to be the other way around: it is the lack of reality testing that is viewed as giving symptoms the quality of psychosis symptoms.

The core questions then remain unanswered: What does it mean to be psychotic? What is a significantly impaired reality testing? What is the relation between psychosis and significantly impaired reality testing? Recognising that legal and forensic practice do not provide us with clear answers, we will now proceed deeper into the medical research perspective in order to seek for further clarifications.

\section{Adding a Medical Research Perspective: Central Premises}

Our discussion so far has made it clear that the criminal insanity rules derive their meaning not only from law, but also from psychiatry. This hybrid character of criminal insanity regulation and practice is not unique to Norway. In fact, the legal doctrine of criminal insanity must be understood as a fundamental legal doctrine that is anchored in certain basic normative claims found in most legal orders. ${ }^{69}$ More specifically, this doctrine is rooted in two fundamental normative claims: that humans generally possess the capacity for responsible behaviour; and, that mental impairments can hamper this capacity. Criminal insanity therefore relies not only on legal and legal-philosophical premises, but also on empirical premises concerning how mental disorders affect the individual. It is in the context of this empirical dimension of criminal insanity that the involvement of forensic experts in legal judgments must be understood.

However, the forensic practice is, as we have discussed, a clinical practice with many (and not always clearly articulated) different perspectives on psychosis. Al-

69 See Yeo, 'The Insanity Defense in the Criminal Laws of the Commonwealths of Nations', Singapore Journal of Legal Studies (2008) pp. 241-263. 
though this practice is to a certain extent anchored in mental health research, it is still a practical field. In this light, a more focused view on mental health research may serve to further illuminate the legal relevance of psychosis and how it may be proved.

It must, however, be kept in mind that there are also many challenges in trying to understand legal constructs through a medical research lens. Clearly, medicine has other purposes and other terms for classification than law when it comes to defining mental states as abnormal. Clinical-empirical studies are often carried out within a diagnostic framework ${ }^{70}$ not developed for legal purposes, but to identify and treat mental disorders. The medical research literature is also extensive and covers many different fields of research, with different perspectives on mental disorders. The field of law and neuroscience that has-particularly in the United States-developed into an extensive discourse ${ }^{71}$ is also hampered by philosophical problems, and philosophers have challenged neuroscience's ability to guide the law. ${ }^{72}$ Bearing these challenges in mind, it is our ambition in the following to investigate the potential to gain a clearer understanding from medical research of both psychosis and impaired reality testing. Perhaps we can draw some insights from this research that can contribute also to a clearer legal understanding of psychosis as a core condition for criminal insanity.

\section{Seeking a Definition of Psychosis Through Medical Research}

\subsection{Impaired Reality Testing and the Core Symptoms of Psychosis}

Most mental health research in recent decades is based on descriptive consensus-based diagnostic manuals, the DSM and the ICD. Accordingly, looking closely into these manuals is an appropriate place to start when asking for a common medical understanding of psychosis. However, neither the ICD-10 or the DSM-5 have a formal definition of the term psychosis. The DSM-5 defines 'psychotic features' as 'features characterised by delusions, hallucinations, and formal thought disorder, ${ }^{73}$ and in the ICD-10 the term 'psychotic' describes 'the presence of hallucinations, delusions, or a or a limited number of severe abnormalities of behaviour, such as gross excitement

70 Cuthbert, 'The RDoC framework: facilitating transition from ICD/DSM to dimensional approaches that integrate neuroscience and psychopathology', World Psychiatry 13(1) (2016) pp. 28-35.

71 Morse \& Roskies, A Primer on Criminal Law and Neuroscience: A Contribution of the Law and Neuroscience Project, Supported by the MacArthur Foundation (Oxford University Press 2016), and Shen, 'Law and neuroscience 2.0', Arizona State Law Journal 48(4) (2016) pp. 1043-86.

72 Morse, 'Legal insanity in the age of neuroscience', in Moratti \& Patterson (eds.), Legal Insanity and the Brain: Science, Law and European courts (Hart Publishing 2016) pp. 239-276, and Maoz \& Yaffe, 'What does recent neuroscience tell us about criminal responsibility?' Journal of Law and the Biosciences 3(1) (2016) pp. 120-39. 
and overactivity, marked psychomotor retardation, and catatonic behaviour'. ${ }^{74} \mathrm{Al}-$ though Norwegian forensic practitioners use the ICD-10, most research is conducted following the DSM. Hence, in the following we will mostly refer to the DSM.

The lack of a clear definition of psychosis has led scholars to suggest that reality distortion could be a common denominator of psychosis. ${ }^{75}$ Psychosis symptoms are, from this perspective, viewed as signs of such a reality distortion.

'If we ask ourselves why symptoms [...] are called psychotic, we find that this serves to indicate that we consider them severe, and that we suspect them to signal a loss of contact with reality [emphasis added] and/or a lack of insight? ${ }^{76}$

Following this line of thought, we will investigate into the three core symptoms- delusions, hallucinations, and thought disturbances-and how these symptoms relate to the impaired reality dimension (reality distortion or loss of contact with reality) of psychosis. As we will discuss in the following, this relation is not clear cut. The psychosis symptoms vary in intensity and associated functional impairment, both within and between persons. Moreover, the symptoms are not categorical. They exist along a continuum from normal experiences and thought processes to severe psychopathology - they are, in other words, dimensional in character. We must also consider how the objective, operational criteria for mental disorders relate to the subjective phenomena underpinning the symptoms, as captured by the phenomenological approach. The objective criteria-based diagnostics and the subjective qualitative experiences are not contradictory, but rather complementary approaches to describing the same clinical phenomena on different levels. In the following, we will use a combined phenomenological and symptom-oriented approach to explore, first, how each of the three symptom domains (delusions, hallucinations, and thought disorders) are related to impaired reality testing. Then, we will go on to discuss possible medical correlates to the legal term 'significantly impaired reality testing', alongside attempts to prove significantly impaired reality testing in a medical context.

\subsection{Impaired Reality Testing and Delusions}

Delusions are, according to the DSM-5, defined as 'fixed beliefs that are not amenable to change in light of conflicting evidence (e.g. persecutory, referential, somatic, religious, grandiose). [...] The distinction between a delusion and a strongly held idea is sometimes difficult to make and depends in part on the degree of conviction with which the belief is held despite clear and reasonable contradictory evidence regard-

74 World Health Organization, The ICD-10 Classification of Mental and Behavioural Disorders: Clinical Descriptions and Diagnostic Guidelines, (World Health Organization 1992).

75 Gaebel \& Zielasek, 'Focus on psychosis', Dialogues in Clinical Neuroscience 17(1) (2015) pp. 9-18.

76 Waters, Blom, Jardri, et al., 'Auditory hallucinations, not necessarily a hallmark of psychotic disorder', Psychological Medicine 48(4) (2017) pp. 1-8. 
ing its veracity.'77 Scholars have used the definitions 'uncorrectable beliefs not shared by others' or 'false representations of reality', ${ }^{78}$ and delusions have been characterised as 'alterations in the patient's subjective framework with its interconnecting perspectives on himself, world, and others. ${ }^{\prime 79}$ The latter suggests that delusions stem from a core psychological disturbance and are of a different quality than false or untrue beliefs. ${ }^{80}$ Delusions may be present in psychotic disorders such as schizophrenia, delusional disorder, and bipolar disorder, but may also appear in disorders not primarily classified as psychotic, such as depression, emotionally unstable personality disorder, dementia, and obsessive-compulsive disorder. ${ }^{81}$ That is, delusions are not in themselves diagnostic markers of a specific disorder.

Furthermore, delusions are part of a continuum of beliefs where the most severe are considered to be delusions of control, influence, thought broadcasting, and bizarre delusions. These kinds of delusions are the so-called 'a-criteria' for a diagnosis of schizophrenia and are easy to distinguish from normal beliefs. However, it may be difficult to make a clinical determination of when a non-bizarre idea crosses the threshold from normality to delusion. The clinical concept of 'overvalued ideas' is intended to be helpful in this regard. Overvalued ideas are placed on the continuum between normal ideas and delusions and are defined as 'an unreasonable and sustained belief that is maintained with less than delusional intensity (i.e., the person is able to acknowledge the possibility that the belief may not be true). ${ }^{92}$

The distinction between overvalued ideas and delusions has, however, been problematised. In the Norwegian 22 July case there was, as we have already touched upon, a broad forensic and public discussion of whether the perpetrator's beliefs were delusional. In the aftermath of this case, some scholars launched the new concept of an 'extreme overvalued idea. ${ }^{83}$ This was meant to capture the perpetrator's 'rigidly held extreme beliefs' that were not psychotic, and not reaching delusional character. ${ }^{84}$ The established term 'overvalued idea' was considered to not cover the full complexity of the continuum between non-psychotic extreme ideas and delusions with impaired reality testing (i.e., psychosis). However, even the introduction of this new term did not solve the clinical challenge of correctly classifying extreme and/or idiosyncratic

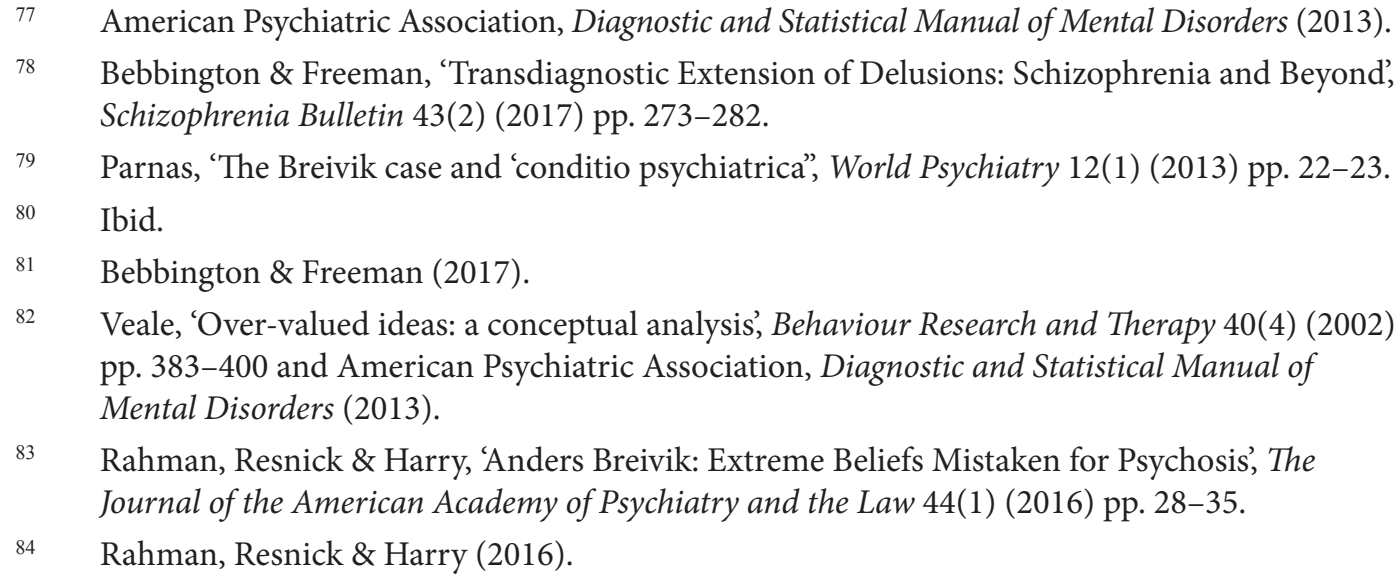


beliefs. Other scholars argued that the 22 July perpetrator's 'extreme beliefs met the definition of delusion, the core symptom of psychosis, ${ }^{85}$ because, even though his racist views were shared by other extremists, the 'beliefs about his specific role in present and future cleansing projects seemed to be more markedly delusional and idiosyncratic'. ${ }^{86}$ Indeed, it was later emphasised that the main difference between the forensic expert report that evaluated the perpetrator as psychotic (i.e., criminally insane) and the one that evaluated him as non-psychotic (i.e., criminally sane) nine months later was that, in the latter evaluation, the perpetrator 'appeared more open to alternative explanations concerning his own role, which made the reality testing [emphasis added] regarding his grandiose notions appear less impaired'. ${ }^{87}$ That is, the thoughts/beliefs which the first pair of forensic experts classified as grandiose delusions, the second pair classified as extremist beliefs. In the first report, the reality testing related to his grandiose ideas was impaired, in the second it was not.

This core difference between the two reports again points towards impaired reality testing as the core of delusions as a psychotic phenomenon. As the discussion about the 22 July case shows, this threshold is difficult (if not impossible) to define on the basis of ideas or beliefs alone because different scholars and clinicians interpret the beliefs differently. The literature does, however, emphasise the importance of a change in the quality of the beliefs when they cross the threshold to delusions and this change in quality parallels the transition to reality distortion. That is, the presence of delusions implies impaired reality testing (and psychosis) and impaired reality testing implies that the beliefs have reached delusional character. The psychosis symptom delusions correspond with the qualitative or phenomenological transition from intact to impaired reality testing.

\subsection{Impaired Reality Testing and Hallucinations}

The DSM-5 defines hallucinations as 'perception-like experiences that occur without an external stimulus. They are vivid and clear, with the full force and impact of normal perceptions, and not under voluntary control' ${ }^{88}$ For auditory hallucinations, scholars have used various definitions including 'misperception of inner experiences and thoughts', 'misattribution of speech', or 'internally generated events that are interpreted as being externally generated' ${ }^{89}$ Hallucinations appear across senses,

85 Merikangas, 'Extreme Beliefs Mistaken for Psychosis', The Journal of the American Academy of Psychiatry and the Law 44(3) (2016) p. 407.

86 Bortolotti, Broome, Mameli, 'Delusions and Responsibility for Action: Insights from the Breivik Case', Neuroethics 7(3) (2014) pp. 377-382.

87 Melle (2013).

88 American Psychiatric Association, Diagnostic and Statistical Manual of Mental Disorders (2013).

89 Hugdahl, 'Auditory hallucinations: A review of the ERC 'VOICE' project', World Journal of Psychiatry 5(2) (2015) pp. 193-209. 
and can be auditory, visual, olfactory (smell), or tactile. The most frequent hallucinations in psychosis are the auditory, which affects about $70-80 \%$ of patients with schizophrenia. ${ }^{90}$ Like delusions, hallucinations also exist across diagnostic boundaries. They may be present in psychiatric disorders that are not primarily defined as psychotic, such as borderline personality disorder, dissociative disorder, depression, anxiety, autism, and post-traumatic stress disorder, as well as in non-psychiatric disorders such as Parkinson's disease, stroke, migraine, tumours and sleep disorders (see Waters et $\mathrm{al}^{91}$ for a review). Auditory hallucinations also occur in otherwise healthy individuals. ${ }^{92}$ Accordingly, since hallucinations are not always accompanied with impaired reality testing, lack of insight or disturbed beliefs, they cannot serve to define psychosis by themselves. ${ }^{93}$

In order to distinguish the characteristics of auditory hallucinations in persons with psychosis from those in persons without psychosis (i.e., otherwise healthy individuals), Daalman and colleagues studied over 200 persons and found that the number, the loudness, and the location (inside or outside the head) of the voices did not differ between the groups. The frequency, negative emotional valence, and lack of perceived control over the voices, however, were significantly greater in persons with psychosis, and the negative emotional valence of the voices could predict the presence of a psychotic disorder with almost $90 \%$ accuracy. ${ }^{94}$ This is in concordance with the Norwegian professor of psychology Kenneth Hugdahl, who, after decades of research on auditory hallucinations, argues that they consist of three phenomena: the perceptual experience, the cognitive inability to ignore the voices, and an emotional dimension where the voices have a negative tone. ${ }^{95}$ Whereas the perceptual experience may cross diagnostic borders and occur in healthy individuals, the cognitive and emotional dimension appears to be more related to an actual underlying psychotic disorder or a psychotic state. In accordance with this distinction between the psychotic and non-psychotic dimension of auditory hallucinations, some scholars have suggested to separate the perceptual experience into a diagnosis of 'perceptual disorders' consisting of 'perceptual phenomena causing distress and dysfunction, but without any impaired reality testing. ${ }^{96}$ With this distinction, they argue that the hallucinations become of psychotic character when they represent or co-occur with

\footnotetext{
90 Hugdahl (2015).

91 Waters, Blom, Jardri, et al. (2017).

92 Van Os, Linscott, Myin-Germeys, et al., 'A systematic review and meta-analysis of the psychosis continuum: evidence for a psychosis proneness-persistence-impairment model of psychotic disorder', Psychological Medicine 39(2) (2009) pp. 179-195.

93 Waters, Blom, Jardri, et al. (2017).

94 Daalman, Boks, Diederen, et al., 'The same or different? A phenomenological comparison of auditory verbal hallucinations in healthy and psychotic individuals', The Journal of Clinical Psychiatry 72(3) (2011) pp. 320-325.

95 Hugdahl (2015).

96 Waters, Blom, Jardri, et al. (2017).
} 
reality distortion. There is a change of quality associated with the transition from the perceptual to the psychotic dimension of auditory hallucinations. As Hugdahl writes: 'Clinically, what drains the patient both cognitively, emotionally, and physically is the ongoing 'dialogue' and typically negative comments and commands from the 'voice', which recruits almost all available cognitive resources [...] with the resulting typical signs of reality disorientation [emphasis added]. ${ }^{97}$ The dimension of reality distortion of hallucinations, as opposed to their mere presence, constitutes the core of hallucinations as a psychotic phenomenon.

\subsection{Impaired Reality Testing and Formal Thought Disorder}

The definition of formal thought disorder in the DSM-5 is somewhat vague: 'Disorganized thinking (formal thought disorder) is typically inferred from the individual's speech. [...] Because mildly disorganized speech is common and unspecific, the symptom must be severe enough to substantially impair effective communication'. ${ }^{98}$ In general, disorganised speech comprises the phenomena of loose associations, tangential or unrelated answers, and incoherence. A more precise and useful definition of thought disorder is given in the research literature: 'any disturbance that affects the form of thinking, including the organisation, control, processing, or expression of thoughts. '99 As such, thought disturbances may be understood as a 'disruption in the interconnectivity of meaning and ideas within an individual'. ${ }^{100}$

Like delusions and hallucinations, thought disturbances are trans-diagnostic phenomena which may occur in psychotic disorders such as schizophrenia and bipolar disorder, as well as in primarily non-psychotic disorders such as depression, personality disorders, neurodegenerative disorders, and stress. ${ }^{101}$ The significance of thought disorder in psychosis dates back to Kräpelin and Bleuler (who were the first to describe the condition, and to coin the term 'schizophrenia', respectively). Kräpelin described how the deterioration of mental functions in psychosis resulted in 'derailment' and 'incoherence' of thought processes, that were observable through the patient's speech. ${ }^{102}$ Bleuler described disturbance of thought as the primary manifestation of the 'splitting' of mental functions that he considered to be the core of the

\footnotetext{
97 Hugdahl (2015).

98 American Psychiatric Association, Diagnostic and Statistical Manual of Mental Disorders (2013).

$99 \quad$ Hart \& Lewine, 'Rethinking Thought Disorder', Schizophrenia Bulletin 43(3) (2017) pp. 514-22.

100 Cohen, Le, Fedechko, et al., 'Can RDoC Help Find Order in Thought Disorder?' Schizophrenia Bulletin 43(3) (2017) pp. 503-508.

101 Hart \& Lewine (2017), and Morgan, Coleman, Ulgen, et al., 'Thought Disorder in Schizophrenia and Bipolar Disorder Probands, Their Relatives, and Nonpsychiatric Controls', Schizophrenia Bulletin 43(3) (2017) pp. 523-535.

102 Hart \& Lewine (2017).
} 
disorder he named schizophrenia (literarily meaning 'splitting of the mind'). ${ }^{103}$

Formal thought disturbances are considered objective and directly observable on mental health examinations. This stands in contrast to hallucinations and delusions, ${ }^{104}$ the presence of which are based on subjective reports from the patient on the (sometimes hidden) content of their thoughts. Four qualitative dimensions of thought disorders have been described: Associative looseness, combinatory thinking (perceptions and ideas are combined in an unrealistic or inappropriate manner), disorganised responses (as in confusion or lack of clarity of thought), and idiosyncratic word usage. ${ }^{105}$

Furthermore, the thought disturbances cluster in two main domains: the 'disorganised' and the 'negative, ${ }^{106}$ where the disorganised domain comprises items such as incoherence, loss of goal, and circumstantiality. The negative domain comprises items such as poverty of speech and speech-content, and may be closer to psychotic, i.e., delusional, thought content. ${ }^{107}$ Understandably, these domains are not specific for psychosis, and mild variants of both domains may be present in relatives of psychosis patients and in healthy control groups. ${ }^{108}$ Importantly, the presence of thought disorders has been shown not to differ between currently psychotic and remitted bipolar disorder patients. ${ }^{109}$ This suggests that thought disorders, as such, are independent of a current psychotic state.

How should we then understand the relationship between thought disorders and impaired reality testing? On the one hand, thought disturbances are not in themselves conclusive for either psychosis or reality distortion. On the other hand, they are considered to be a hallmark of psychosis as shown in the early psychosis texts by Kräpelin and Bleuler. Indeed, it has been argued that: 'Breakdowns in the thought system [...] is intrinsically linked to difficulties with psychological and social wellbeing and the ability to function adaptively in the world. At their extreme, these disturbances are the core of psychotic experiences.'110 That is, the presence of formal thought disorders is not sufficient to conclude that a person is psychotic or has impaired reality testing. But on the other hand, the presence of thought disturbances is thought to be at the core of psychosis. Hence, there appears to be no clear-cut

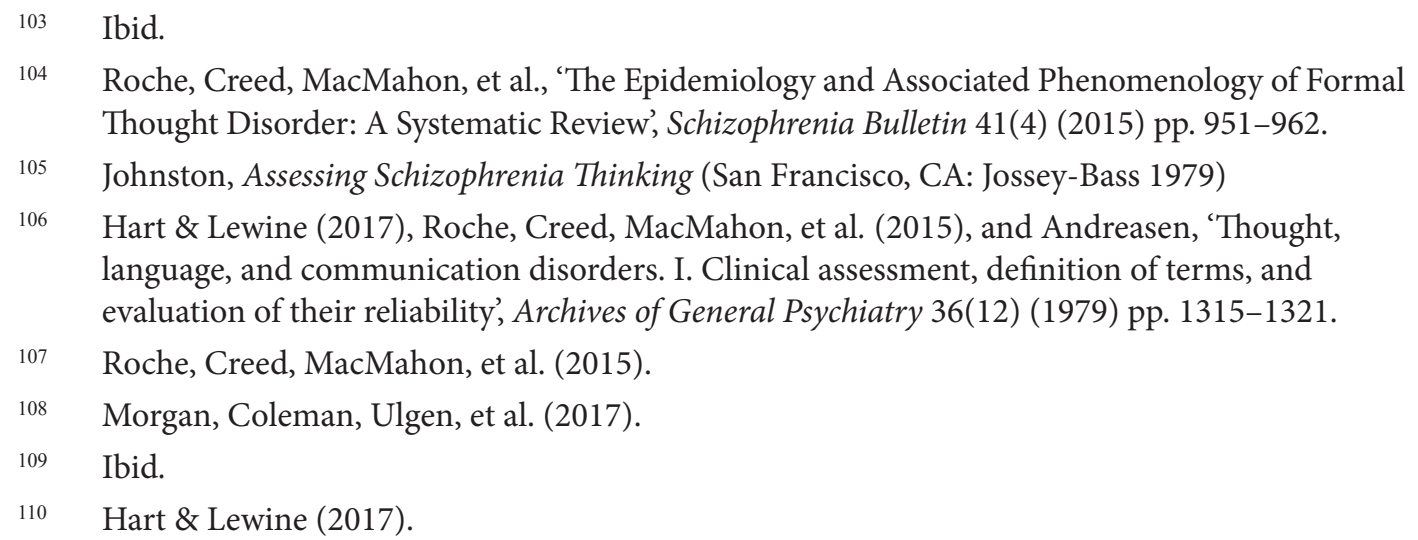


link between thought disturbance as a psychosis symptom and the dimension of impaired reality testing.

\subsection{Understanding the Dimension of Impaired Reality Testing}

From our previous discussion it has become clear that the relation between impaired reality testing and the three core symptoms of psychosis, as understood in the diagnostic manuals, is complex. Ultimately, the psychosis threshold appears to correspond with a qualitative change in ideas/beliefs or perceptions, which amounts to impaired reality testing. That is, a state where the person's ability to have an objective evaluation of the external world and to differentiate between the external world and the internal (their ego or self) is impaired. To a significant extent, it is the presence of impaired reality testing that provides the symptoms with their quality of psychosis symptoms, and at the same time, impaired reality testing manifests itself through these symptoms. This may be as close as we can get to a definition of psychosis based on the general medical research literature. The lack of a uniform approach to psychosis and impaired reality testing, both in law and forensic practice, can thus be traced back to the lack of unified definitions in research.

An even more complicated matter in the intersection between law and medical research concerns the question of the psychosis dimension. As described above, Norwegian law requires significantly impaired reality testing for a defendant to be evaluated as psychotic in a legal context. From a medical research perspective, impaired reality testing seems to correspond with the psychosis threshold as a categorical phenomenon. The question is then, how should we define and potentially prove 'significantly impaired reality testing'?

We will in the following argue that there may be, in principle, different possible approaches to defining and proving significantly impaired reality testing from a medical point of view-but that these approaches need to be further developed. More specifically, the main approaches to such a dimensional understanding of reality distortion are: a quantitative, a qualitative, a functional, and perhaps even a neurobiological/neuroscientific measure. The quantitative approach includes measuring the psychosis symptoms according to validated semi-structured interviews and rating scales. The qualitative approach focuses on the most severe psychopathological symptoms such as delusions of control, commenting auditive hallucinations, or thought broadcasting. The functional approach is linked to cognitive impairments and impaired daily functioning. Finally, a future neurobiological approach could provide objective measures of psychosis severity. These different approaches will be further explained below, in relation to the problem of proving a relevant state of psychosis. 


\section{Identifying Psychosis from a Medical Research Perspective}

On the assumption that we can define a state of psychosis and impaired reality testing, we ought also to able to identify it in a legal context. But how can we prove the presence of psychosis and impaired reality testing, and, more specifically, significantly impaired reality testing? We have previously explained how psychosis and impaired reality testing are generally evaluated through diagnostic tools and phenomenological approaches. Proving the presence of psychosis is the forensic expert clinician's task. A more general question for the research community is, however, whether there are objective neurobiological markers that could facilitate the proving of psychosis on the subject level. To date, such markers have not been found and those methods do not exist. Even though neuroscience has contributed to our understanding of the putative biological mechanisms underpinning psychosis on a general level, we are far from being able to use neuroscientific methods to identify psychosis on the individual level. ${ }^{111}$

Proving psychosis and reality distortion clinically is, however, not sufficient in the legal context. As described, the Norwegian law requires significantly impaired reality testing for a defendant to be evaluated as psychotic in a legal context. Moreover, the offender's failing ability to make a realistic assessment of his relationship to the surrounding world must be relatively general and include significant aspects of reality. In the previous section, we concluded that impaired reality testing seems to correspond with the psychosis threshold as a categorical phenomenon. The question is, then, how should we interpret the legal term 'significantly impaired reality testing'? And importantly, what are the medical correlates to this?

There are different possible approaches to defining and proving significantly impaired reality testing from a medical point of view. Importantly, the way we prove the presence of significantly impaired reality testing will follow from our initial definition of the phenomenon (significantly impaired reality testing). If we define 'significantly' as either a quantitative, qualitative, functional, or even a neurobiological/ neuroscientific measure, we must follow the same axis to prove its presence. The following is thus meant to exemplify and discuss how significantly impaired reality testing might be proved along these four axes.

One simplistic and operational practice would be to quantify the impaired reality testing related psychosis symptoms. Indeed, the DSM-5 has introduced specifiers for psychosis severity. Each psychosis symptom may be classified on a Likert scale from $0-5$ where 2 signifies the presence of the symptom (e.g., hallucination, delusion). This quantification may also be conducted by the use of validated symptom assessment scales such as the Positive and Negative Syndrome Scale (PANSS), which is well known in clinical and forensic practice, as well as in psychosis research. By

111 Frangou, 'A Systems Neuroscience Perspective of Schizophrenia and Bipolar Disorder', Schizophrenia Bulletin 40(3) (2014) pp. 523-531. 
the use of such instruments, the person will get a sum score and a score for specific symptom domains, where a higher score reflects a higher symptom load and hence a greater severity. Hypothetically, a threshold for significant severity could be set at a given sum score. However, not all symptoms included in such sum scores are related to the dimension of impaired reality testing. As such, this quantitative approach may miss the intention to measure significant impairments in reality testing. To compensate for irrelevant items, items especially relevant to reality testing could be defined according to a threshold or summed up, and irrelevant items get omitted.

Another more qualitative approach is to assess the presence of Schneiderian 'first-rank symptoms', which are commanding or commenting auditive hallucinations, thought insertion or thought broadcasting, or delusions of being controlled/ that someone has taken control over the person's body or thoughts. ${ }^{112}$ These specific delusions and hallucinations are considered as particularly severe because they imply a significant reality distortion. Traditionally, the presence of only one of the first-rank symptoms has been sufficient for a diagnosis of schizophrenia, but recently their value for a schizophrenia diagnosis has been questioned. ${ }^{113}$ Other researchers have questioned their sensitivity but confirmed their specificity. ${ }^{114}$ More importantly, as core psychosis symptoms which are considered as significantly affecting reality testing, their presence may point toward fulfilling the significantly impaired reality testing required for the legally relevant psychosis criterion. But, even if the presence of the first-rank symptoms can be considered to fulfil the criteria for significant reality distortion, we still need to define the threshold for significant reality distortion when psychosis symptoms other than the first-rank are present.

A third option could be to address significantly impaired reality testing through functional impairments. Cognitive dysfunction has repeatedly been linked to impaired function in psychosis. ${ }^{115}$ Specifically, the neurocognitive domains of verbal memory and executive functioning are related to functional outcome. ${ }^{116}$ However, neurocognitive performance may be linked to other factors related to psychosis such as medication, relapses and hospitalisations, ${ }^{117}$ and appear to be stable over time and independent of the presence of positive psychosis symptoms (hallucinations, delu-

112 World Health Organization, The ICD-10 Classification of Mental and Behavioural Disorders: Clinical Descriptions and Diagnostic Guidelines, (World Health Organization 1992).

113 Nordgaard, Arnfred, Handest, et al., 'The diagnostic status of first-rank symptoms', Schizophrenia Bulletin 34(1) (2008) pp. 137-154.

114 Heinz, Voss, Lawrie, et al., 'Shall we really say goodbye to first rank symptoms?', European Psychiatry 37 (2016) pp. 8-13.

115 Carrion, McLaughlin, Goldberg, et al., 'Prediction of functional outcome in individuals at clinical high risk for psychosis', JAMA Psychiatry 70(11) (2013) pp. 1133-1142.

116 Green, Kern, Braff, et al., 'Neurocognitive deficits and functional outcome in schizophrenia: are we measuring the 'right stuff'?', Schizophrenia Bulletin 26(1) (2000) pp. 119-136.

117 Carrion, McLaughlin, Goldberg, et al. (2013). 
sions, thought disturbances). ${ }^{118}$ As we discussed above, impaired reality testing corresponds with the presence of delusions, hallucinations, and thought disturbances, but not to cognitive impairments in themselves. It would therefore be insufficient to use functional impairments related to cognitive dysfunction as a measure of significantly impaired reality testing.

Finally, one could (in line with recent neuroscientific research) imagine the future use of biomarkers as a measure of significant impaired reality testing. For instance, MRI studies in psychosis patients have shown reality distortion to be associated with grey matter loss and functional abnormalities in the brain. ${ }^{119}$ If such abnormalities were to be quantified, one could imagine a threshold for significantly impaired reality testing as an objective measure obtained in an MRI-scanner. But, despite the fact that neuroimaging data has increasingly been admitted in US courts, ${ }^{120}$ an inherit limitation of this research is that the results are on the group-level and may not be applicable to single subjects. Moreover, the proven associations are correlational and not causal, and may be affected by confounding factors such as medication. ${ }^{121}$ Even though neuroscientific research may point towards associations and mechanisms underpinning impaired reality testing, neuroimaging is, to date, far from being a reliable approach to measure significantly impaired reality testing in single subjects.

From this discussion, we can conclude that there are quantitative, qualitative and perhaps functional approaches to measuring significantly impaired reality testing as this criterion is formulated in the Norwegian law. However, because there are three different approaches, all of which have limitations, the choice of any one of the three may affect whether a person is evaluated to fulfil the legal psychosis criterion or not.

\section{Discussion and Recommendations}

We have investigated the meaning of psychosis and impaired reality testing as conditions relevant to criminal insanity from the three interrelated perspectives of law, forensic practice, and mental health research. As criminal insanity is a legal construct, although a hybrid one, our point of departure was the law. More specifically, we started with various criteria for criminal incapacity in section 20 of the Norwegian Penal Code, within which criminal insanity is equated with psychosis (as significantly impaired reality testing). This focus on psychosis will remain in Nor-

118 Cornblatt, Carrion, Addington, et al., 'Risk factors for psychosis: impaired social and role functioning', Schizophrenia Bulletin 38(6) (2012) pp. 1247-1257.

119 Frangou (2014).

120 Farahany, 'Neuroscience and behavioral genetics in US criminal law: an empirical analysis', Journal of Law and the Biosciences 2(3) (2015) pp. 485-509.

121 See Fjellvang, Gröning \& Haukvik, 'Imaging Violence in Schizophrenia: A Systematic Review and Critical Discussion of the MRI Literature', Frontiers in Psychiatry 9 (2018). 
wegian law after the expected law reform, and is a core of the insanity regulations of most countries.

From a legal perspective it is particularly important to have clear and robust criminal insanity rules, because these determine who will be held responsible and punished, and who will be acquitted. The justification for the use of a psychosis criterion in the Norwegian Penal Code involves arguments about legal certainty, which leaves the impression that this criterion may function as a clear legal cut-off point.

Our investigation has, however, showed that this is not necessarily the case. Although seemingly concrete, the psychosis criterion used in Norwegian criminal law lacks a clear definition. Forensic evaluations that have large impact on who is/is not viewed as criminally insane are, to a significant extent, based upon clinical discretion within a diagnostic framework that is not suited to legal purposes. Looking at forensic practice in Norway, it becomes clear that the assessment of whether the defendant was (legally) psychotic may be challenging. There is no uniform understanding of how impaired reality testing should be defined and determined in Norwegian forensic practice. Experts may emphasise different criteria and different thresholds for determining if a person was psychotic. The evaluation may be based on prejudices, or on specific conceptions regarding how ill a person must be or how deviant their behaviour must be in order for them to be evaluated as criminally insane, more than the person's reality testing abilities.

The underlying problem seems to be that there is no uniform medical understanding of what it is to be psychotic. Moreover, there is a lack of an operationalisation of impaired reality testing, and the law's requirement of significantly impaired reality testing thus has no obvious medical reference point. This lack of a clear definition of psychosis is also reflected in the practical challenges in proving the relevant state of psychosis. Many practical challenges are also related to the fact that criminal insanity evaluations require evaluating the defendant's state of mind in retrospect. The dimensional character of psychopathology also poses a general challenge when medicine meets law, where a binary answer is required as to whether the perpetrator is criminally sane and responsible or not.

How can we address these challenges? Given that criminal insanity should be related to psychosis, we need to develop clearer legal cut-off points, and clearer guidelines for forensic practice and the forensic interview. A good interview must, in our view, include questions that shed light on the person's perception of him/herself and others, rather than focusing exclusively on symptoms and signs. Through their interview, the experts must also chart the person's ability to change between perspectives, and if the person's concept of reality has changed or been stable over time and across different situations. ${ }^{122}$

122 See Jansson \& Parnas, 'Competing Definitions of Schizophrenia: What Can Be Learned From Polydiagnostic Studies?', Schizophrenia Bulletin 33(5) (2006) pp. 1178-1200 on the need to integrate a phenomenological perspective. 
This development of clearer legal cut-off points and forensic guidelines in turn requires the development of clearer legal, medical, and maybe also medio-legal definitions. Throughout the work with this article it has become increasingly clear to us that the law is seeking answers from the medical and neuroscientific research communities that these disciplines, to date, cannot provide. Law and medicine relate to distinct research fields, and the concepts and terminology regarding insanity and psychosis differ between the two.

Ultimately, the lack of a clear understanding in law thus points towards the need for further research. Moving forward requires considering the characteristics of law and medicine (in both its practical and clinical dimensions) together, and developing research at the intersection between them. Hopefully this article has made some contributions in that direction. 